\title{
Research on Implementation of Green Manufacturing Strategy Decision Method of Enterprise Based on AHP
}

\author{
Chaohua Wu, Lei Chen
}

School of Mechanical and Electrical Engineering, Wuhan University of Technology, Wuhan 430070, China

Keywords: Green, AHP, Manufacturing, Decision, Enterprise

\begin{abstract}
In order to improve the level of green manufacturing, advanced manufacturing enterprises usually adopt source control and terminal control.How to choice the way of control is the main content of this paper.The article establishes implementation of green manufacturing strategic decisions evaluation model to comprehensive evaluate by establishing judgment matrix, the level of the single criteria ranking and consistency checking, sorting and comprehensive level consistency inspection.taking an enterprise as an example, it makes a comprehensive evaluation on the adoption of source control and terminal control from the aspect of improvement of market resilience,improvement of technical level,improvement of management level,improvement of service level, improvement of service level. The results show that source control is more in line with the strategic decision making.
\end{abstract}

\section{Introduction}

Since Society of Manufacturing Engineers,USA proposed green manufacturing in 1996,domestic and foreign scholars have done a lot of research on green manufacturing.[1].At present the manufacturing enterprises to implement green manufacturing is used for source control and terminal control.The source control is a comprehensive consideration of environmental impact generated in the manufacturing process in the stage of product design,Coordinating the relationship between economic, social and environment at the strategic level.It controls the environmental pollution source from the decision-making to the generation and the destruction of the ecological environment, to ensure that the impact on the environment of green products manufacturing process of minimum, the highest resource utilization efficiency.Terminal control refers to the end of the production process, pollutants generated for manufacturing product development and implementation of effective management technique[2]. How to evaluation based on green manufacturing technology source control and end control based on green manufacturing technology is main problem for modern policymakers.

\section{Analytic Hierarchy Process(AHP)}

The basic idea of AHP is the total goal will be decomposed into several sub goal evaluation, then the sub target calculates the relative weight according to evaluation aspects of evaluation.Finally, the total objective comparison, comparative data from the final decision can often be an optimal solution, meet the set target[3].

The basic steps of AHP is:

\section{Step1: Constructing model}

It will be a predetermined target as the goal layer, achieve the goal of each evaluation as part of the criterion layer, the lowest layer is the plan layer, which is showed in Figure 1. 


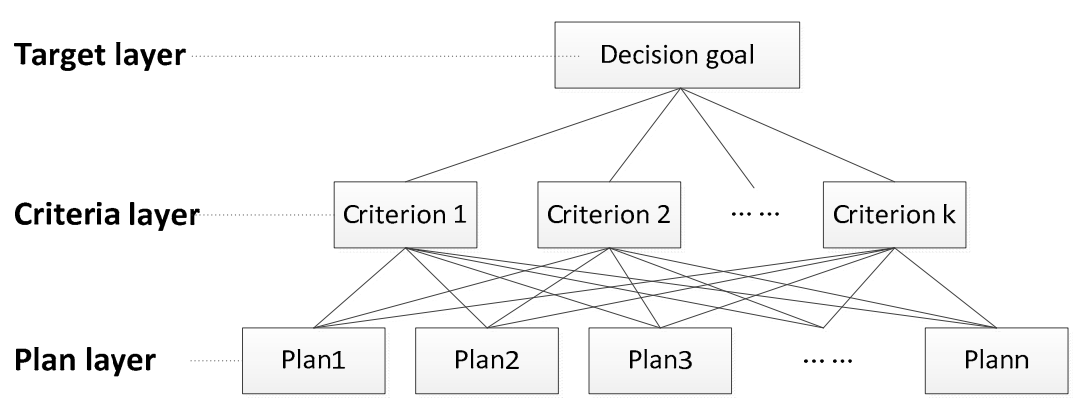

Fig. 1:The hierarchical structure of AHP

\section{Step2: Establishing judgment matrix}

After the establishment of the hierarchy model, subordinate relationship between target layer, criteria layer and plan layer element has been determined, for easy comparison of each factor under a layer and a layer of selected relatively important degree[4].The evaluation index of relative importance degree judgment scale indicated by 1-9 is showed in Table 1 .

Table 1:The evaluation index of relative importance degree judgment scale

\begin{tabular}{|c|c|}
\hline scale & Meaning (Representation for A) \\
\hline 1 & $\begin{array}{c}\text { Comparison of factor } \\
\text { equally important }\end{array} B_{i}$ and factor $B_{j}, B_{i}$ and $B_{j}$ are \\
\hline 3 & $\begin{array}{c}\text { Comparison of factor } B_{i} \text { and factor }{ }^{B_{j}}, B_{i} \text { is slightly } \\
\text { important }\end{array}$ \\
\hline 5 & 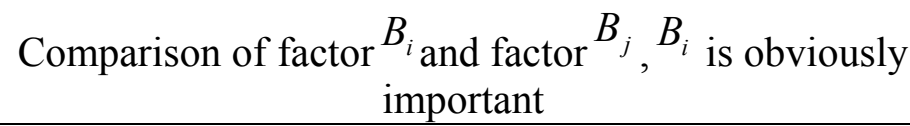 \\
\hline 7 & $\begin{array}{c}\text { Comparison of factor } B_{i} \text { and factor } B_{j}, B_{i} \text { is more } \\
\text { important }\end{array}$ \\
\hline 9 & $\begin{array}{c}\text { Comparison of factor } \begin{array}{c}B_{i} \text { and factor } \\
\text { important }\end{array} B_{j}, B_{i} \text { is absolutely } \\
\text { impon }\end{array}$ \\
\hline $\begin{array}{c}2,4,6 \\
8\end{array}$ & Between two adjacent judgment scale \\
\hline & Note: Contrary to take reciprocal \\
\hline
\end{tabular}

$\mathrm{b}_{i j}$ in the Judgment matrix refers to the degree of importance of indicator 1 relative to 2.That is

From the above equation

$$
b_{i j}=\frac{W_{i}}{W_{j}}
$$

$$
b_{i i}=1
$$

$b_{i j}=\frac{1}{b_{i j}}(i, j=1,2,3, \ldots, n)$

Through the above comparison, we can get the judgment matrix.To ensure the objectivity of comparative data, $b_{i j}$ is based on data, expert opinions and analysts awareness.

Step3: Single level criteria ranking and consistency inspection

Single criteria ranking refers to the calculation of relative weights of criteria for a next element according to the judgment matrix,For each element of the criterion layer, a weight vector $W=\left(w_{1}, w_{2}, w_{3}, \ldots, w_{i}, \ldots, w_{n}\right)^{T}$,Obtained by solving the following equation.

$$
A W=\lambda_{\max } W
$$


In the formula, $\lambda_{\max }$ is the largest eigenvalue of the judgement matrix A.W is the normalized eigenvector corresponding to the ${ }^{\lambda_{\max }}$.Component of $\mathrm{W},{ }^{w_{i}}$ is the corresponding weight value of single sort elements.

If the judgment matrix $\mathrm{B}$ has the complete consistency, $\lambda_{\max }={ }_{n}$. However, in general it is not necessarily consistent.In order to test the consistency of judgment matrix, we need to compute the consistency index.

$$
C I=\frac{\lambda_{\max }-n}{n-1}
$$

When $\mathrm{CI}=0$,judgment matrix is completely consistent.The greater the $\mathrm{CI}$, the consistency of the judgment matrix is worse.In order to test whether the judgment matrix with satisfactory consistency, we need to compare CI with RI(The average random consistency index)[5].

In general, the judgment matrix of 1 or 2 order is always with complete consistency.For the judgment matrices of order 2 or more, ratio of the consistency index CI with the same order of mean random consistency index RI (Table 2), called the stochastic judgment matrix consistency ratio, denoted as $\mathrm{CR}$.

$$
\text { When } C R=\frac{C I}{R I}<0.10
$$

$C R \geq 0.10$,it need to adjust the judgment matrix until satisfied.

Table 2:The average random consistency index RI value

\begin{tabular}{|c|c|c|c|c|c|c|c|c|c|c|c|c|c|c|c|}
\hline $\begin{array}{c}\text { numb } \\
\text { er }\end{array}$ & 1 & 2 & 3 & 4 & 5 & 6 & 7 & 8 & 9 & 10 & 11 & 12 & 13 & 14 & 15 \\
\hline RI & 0 & 0 & 0.5 & 0. & 1.1 & 1.2 & 1.3 & 1.4 & 1.4 & 1.4 & 1.5 & 1.5 & 1.5 & 1.5 & \\
R & 0 & 8 & 9 & 4 & 2 & 1 & 5 & 9 & 2 & 4 & 6 & 8 & 1.59 \\
\hline
\end{tabular}

\section{Evaluation model of green manufacturing strategy decision}

The implementation of green manufacturing strategy decision-making mainly includes the following contents:

\section{Improvement of market resilience}

With growing awareness of low-carbon environment, consumers increasingly want to buy green products.At present, the governments of the world have made strict environmental requirements of mechanical products. The implementation of green manufacturing can comply with the requirements of low carbon environmental protection.

\section{Improvement of technical level}

In the basis of the existing technical conditions, the development of products using the green design and manufacturing technology, the existing production line technological transformation of energy saving, pollution reduction and pollution reducing and the remanufacturing, enhance the core competitiveness of products. Improve the level of technology is the technical support of green manufacturing enterprises to implement. Green design is different from the traditional design method, it fully consider the product in use and recovery stage of environmental impact and resource consumption, make the enterprise economic benefit and social benefit coordination optimization.

\section{Improvement of management level}

In order to enterprise resources, energy, product information and effective management, the implementation of green manufacturing must improve its management means, raise the level of management can effectively promote the enterprise in the production, scheduling, sales and other aspects of the decision-making level, reduce mistakes in decision-making, improving the utilization ratio and the production efficiency of all kinds of resources. 


\section{Improvement of service level}

With the progress of science and technology, product technology is more and more complex, consumers for more enterprises depend more and. They buy products. Not only the purchase of the product itself, but also hope to purchase products, reliable and considerate service. Enterprise quality assurance, service commitment, service attitude and service efficiency, has become a consumer to determine the quality of products, an important condition to decide to buy or not. For the production of a variety of devices and durable consumer goods enterprise, make product service is particularly important, can enhance the enterprise's competitive ability, to win the chance to repeat purchase.

\section{The promotion of enterprise image}

Green manufacturing products using modern design method from the product life cycle, production organization, not only can bring huge economic benefits to the user, but also can solve the current global facing resource depletion, energy shortage and environmental pollution problems. This is helpful for the establishment of brand and enhance the corporate image, these are conducive to business cooperation enterprises inside and outside the enterprise or institution with the country remain stable cooperation opportunities and conditions[6].

\section{The example analysis}

In order to meet government requirements for energy conservation, a machinery manufacturing company decided to have some sort of product transformation process, There are two kinds of scheme, source control and terminal control.comprehensive index system to evaluate the efficiency of the scheme as shown in the table 3.

Table 3:Alternative dimensionless utility value

\begin{tabular}{|c|c|c|c|}
\hline Item & Symbol & $\begin{array}{c}\text { Source } \\
\text { control }\end{array}$ & $\begin{array}{c}\text { Terminal } \\
\text { control }\end{array}$ \\
\hline Improvement of market resilience & $\mathrm{V} 1$ & 0.35 & 0.61 \\
\hline Improvement of technical level & $\mathrm{V} 2$ & 0.90 & 0.55 \\
\hline Improvement of management level & $\mathrm{V} 3$ & 0.66 & 0.54 \\
\hline Improvement of service level & $\mathrm{V} 4$ & 0.45 & 0.68 \\
\hline The promotion of enterprise image & $\mathrm{V} 5$ & 0.92 & 0.32 \\
\hline
\end{tabular}

\section{Establishing judgment matrix and the relative weights.}

Green manufacturing strategic decisions by five factors that constitute requires judgment matrix to determine the weight of each element of the weight of more than 30 industry experts to carry out the survey, the guidelines of each layer to judge the relative importance of the elements, through statistical analysis to determine matrix, as shown in Table 4.

Table 4:Strategic decision of judgment matrix

\begin{tabular}{|c|l|l|l|l|l|l|l|}
\hline Strategic decision & A1 & A2 & A3 & A4 & A5 & $W_{i}$ & $W_{i}$ \\
\hline $\begin{array}{c}\text { A1:Improvement of } \\
\text { market resilience }\end{array}$ & 1 & 1 & 4 & 3 & 7 & 2.426 & 0.351 \\
\hline $\begin{array}{c}\text { A2:Improvement of } \\
\text { technical level }\end{array}$ & 1 & 1 & 5 & 4 & 8 & 2.759 & 0.399 \\
\hline $\begin{array}{c}\text { A3:Improvement of } \\
\text { management level }\end{array}$ & $1 / 4$ & $1 / 5$ & 1 & 1 & 2 & 0.631 & 0.089 \\
\hline $\begin{array}{c}\text { A4:Improvement of } \\
\text { service level }\end{array}$ & $1 / 3$ & $1 / 4$ & 1 & 1 & 4 & 0.803 & 0.116 \\
\hline $\begin{array}{c}\text { A5:The promotion of } \\
\text { enterprise image }\end{array}$ & $1 / 7$ & $1 / 8$ & $1 / 2$ & $1 / 4$ & 1 & 0.295 & 0.043 \\
\hline
\end{tabular}




$$
\text { Judgment matrix } A=\left[\begin{array}{ccccc}
1 & 1 & 4 & 3 & 7 \\
1 & 1 & 5 & 4 & 8 \\
\frac{1}{4} & \frac{1}{5} & 1 & 1 & 2 \\
\frac{1}{3} & \frac{1}{4} & 1 & 1 & 4 \\
\frac{1}{7} & \frac{1}{8} & \frac{1}{2} & \frac{1}{4} & 1
\end{array}\right]
$$

Using the square root method for judging the maximum eigenvalues of matrix $A$.

$\mathrm{M}_{1}=1 \times 1 \times 4 \times 3 \times 7=84 ; \mathrm{M}_{2}=1 \times 1 \times 5 \times 4 \times 8=160$;

$$
\begin{aligned}
& \mathrm{M}_{3}=\frac{1}{4} \times \frac{1}{5} \times 1 \times 1 \times 2=0.100 ; \mathrm{M}_{4}=\frac{1}{3} \times \frac{1}{4} \times 1 \times 1 \times 4=0.333 ; \\
& \mathrm{M}_{5}=\frac{1}{7} \times \frac{1}{8} \times \frac{1}{2} \times \frac{1}{4} \times 1=0.002 ;
\end{aligned}
$$

Calculating of the $\mathrm{n}$ root of $M_{i}$

$$
\begin{aligned}
& \bar{W}_{1}=\sqrt[5]{M_{1}}=\sqrt[5]{84}=2.426 ; \bar{W}_{2}=\sqrt[5]{M_{2}}=\sqrt[5]{160}=2.759 \\
& \bar{W}_{3}=\sqrt[5]{M_{3}}=\sqrt[5]{0.100}=0.631 ; \bar{W}_{4}=\sqrt[5]{M_{4}}=\sqrt[5]{0.333}=0.803 \\
& \bar{W}_{5}=\sqrt[5]{M_{5}}=\sqrt[5]{0.002}=0.295
\end{aligned}
$$

Normalizating

$$
\begin{gathered}
\sum_{i=1}^{5} W_{5}=(2.426+2.759+0.631+0.803+0.295)=6.914 \\
W_{1}=0.351 ; W_{2}=0.399 ; W_{3}=0.089 ; W_{4}=0.116 ; W_{5}=0.043 \\
W=\left[\begin{array}{l}
0.351 \\
0.399 \\
0.089 \\
0.116 \\
0.043
\end{array}\right] \\
\lambda_{\max }=\sum_{i=1}^{n} \frac{(A W)_{i}}{n W_{i}}=\frac{1.755}{5 \times 0.351}+\frac{2.003}{5 \times 0.399}+\frac{0.459}{5 \times 0.089}+\frac{0.565}{5 \times 0.116}+\frac{0.222}{5 \times 0.043}=5.043
\end{gathered}
$$

So the consistency index for matrix

$$
C I=\frac{\lambda_{\max }-n}{n-1}=\frac{5.043-5}{5-1}=0.011<0.10
$$

According to the matrix of $\mathrm{n}$ order mean random consistency index $\mathrm{RI}=1.12$, therefore the matrix relative consistency index

$$
\mathrm{CR}=\frac{C I}{R I}=\frac{0.011}{1.12}=0.010<0.10
$$

From the result,judgment matrix A have good consistency. 


\section{Calculation of the weights of evaluation indexes.}

The utility matrix corresponds to the strategic benefit index

$$
V=\left[\begin{array}{ll}
0.35 & 0.61 \\
0.55 & 0.90 \\
0.66 & 0.54 \\
0.68 & 0.45 \\
0.92 & 0.32
\end{array}\right]
$$

The weight vector is $\mathrm{W}^{\mathrm{T}}$. $\mathrm{U}$ is the alternative evaluation matrix.

$$
\begin{aligned}
& \mathrm{U}=\mathrm{W}^{\mathrm{T}} \mathrm{V}=\left[\begin{array}{lllll}
0.351 & 0.399 & 0.089 & 0.116 & 0.043
\end{array}\right]\left[\begin{array}{cc}
0.35 & 0.61 \\
0.90 & 0.55 \\
0.66 & 0.54 \\
0.45 & 0.68 \\
0.92 & 0.32
\end{array}\right] \\
& =\left[\begin{array}{ll}
0.634 & 0.574
\end{array}\right]
\end{aligned}
$$

\section{Conclusion}

By multi factor comprehensive evaluation for green manufacturing strategy benefits and analysis, using AHP analysis method, we evaluated the alternative matrix can be obtained from the conclusion that the source control of the utility value is higher than terminal control of the utility value. In this case, in order to better implementation of green manufacturing strategy benefits, Source control is more in line with the strategic decision making. The research methods and results of the implementation of green manufacturing is useful for green manufacturing strategy decision.

\section{Acknowledgment}

This research work was financially supported by the horizontal subject (No.20112h243).Lei Chen is Corresponding Author.

\section{References}

[1] MelngkSA, SmithRT. Green manufacturing[M].Dearborn, USA: Societ of Manufacturing Engineers.1996

[2] LIU Fei. Theory and technology of green manufacturing[M]. Beijing:Science Press, 2005.

[3] Wang Jinsong, Duan Guanghong,Li Fangyi,et. Current situation and future developing trends of green manufacturing technology based on products life cycle[J].Computer Integrated Manufacturing Systems, 1999,5(4):1-8.

[4] HE Y,LIU F, CAO H J. Process planning support system for green manufacturing and its application[J].Frontiers of Mechanical Engineering in China,2007,2(1):104-109.

[5] SIVAPIRAKASAM S P, MATHEW J, SURIANARAYA-NAN M. Multi-attribute decision making for green electrical discharge machining[J]. Expert Systems with Applications,2011,38: 8370-8374.

[6] CHU M T, SHYU J, TZENG G H, et al. Comparison among three analytical methods for knowledge communities group-decision analysis[J]. Expert Systems with Applications, 2007, 33(4):1011-1024. 